\title{
Biological Fronts in the Strait of Georgia, British Columbia, and Their Relation to Recent Measurements of Primary Productivity
}

\author{
T. R. Parsons ${ }^{1}$, J. Stronach ${ }^{2}$, G. A. Borstad ${ }^{3}$, G. Louttit ${ }^{4}$ and R. I. Perry ${ }^{1}$ \\ 1 Department of Oceanography, University of British Columbia, Vancouver, B. C., Canada \\ 2 Beak Consultants Ltd., 1550 Alberni Street, Vancouver, B. C., Canada \\ ${ }^{3}$ Seakem Oceanography Ltd., 9817 West Saanich Road, Sidney, B. C., Canada \\ 4 Department of Biology, University of Victoria, B. C., Canada
}

\begin{abstract}
Frontal regions of high chlorophyll fluorescence in the Strait of Georgia have been compared with calculated values of the stability expression, $\log _{10}\left(\mathrm{~h}^{-3}\right)$. Boundary areas of high chlorophyll were shown to exist at the northern and southern ends of the Strait as well as among the different island groups. These results have been used to discuss earlier differences noted in average annual primary productivity values of the Strait of Georgia, as observed over the last decade.
\end{abstract}

\section{INTRODUCTION}

It was recently suggested (Parsons et al., 1980) that the distribution of phytoplankton in the Strait of Georgia (Canada) would be found to be maximized in frontal boundary areas, where primary productivity values are greatly enhanced due to the entrainment of nutrients from below the pycnocline. This phenomenon is particularly apparent during the summer months when surface nutrients are generally low in concentration; the mechanism has been described by Pingree (1978) for the Celtic Sea. The critical measurement used to describe a front by Pingree (1978) was the term $\log _{10}\left(\mathrm{~h} \mathrm{u}^{-3}\right)$, where $\mathrm{h}$ is water depth in $\mathrm{cm}$ and $\mathrm{u}$ vertically averaged water velocity in $\mathrm{cm} \mathrm{s}^{-1}$ during tidal exchange. If the drag coefficient term $\left(C_{d}\right)$ in Pingree's original expression is omitted as being approximately constant under similar conditions in which we wish to analyse frontal zones, then the zones of chlorophyll a maxima should occur above a threshold value of ca -1.0 , assuming a constant heat flux, $Q$, as in the original equation (Pingree, 1978). Values below -1.0 should generally reflect too great a turbulence to allow for primary productivity to occur, while values much in excess of -1.0 would inhibit primary productivity due to stabilization and nutrient exhaustion. The actual relationship of chlorophyll a to the threshold value of -1.0 must be found experimen- tally since it will depend on such additional factors as local circulation and grazing. The chlorophyll a maximum would generally be expected to occur, however, at values of greater than -1.0 (i.e. postpositioned to an increase in primary productivity).

In the following account we have calculated the same term for waters of the Strait of Georgia and compared the results with measurements of chlorophyll a concentration made by airborne remote sensing and ship-borne continuous sensor. The timing of the study, July 29 to August 2, 1980, was chosen in order to examine chlorophyll concentrations during a period when a maximum contrast might be observed between frontal zones and nutrient depleted areas of relative stability. These results are discussed in terms of earlier observations on differences in the primary productivity reported for the Strait of Georgia.

\section{METHODS}

Chlorophyll a was measured from the R. V. 'Strickland' using a continuous flow fluorometer (Strickland and Parsons, 1972) and a water intake depth of approximately $1 \mathrm{~m}$ (Fig. $1 \mathrm{C}$ ). The instrument was standardized at approximately 10 mile intervals by extracting and analysing samples of chlorophyll. The cruise was carried out from July 28 to August 2, 1980. 
Airborne measurements of surface layer chlorophyll a concentrations were conducted August 2, 1980 using the Institute of Ocean Sciences colour spectrometer (Walker et al., 1974). This instrument was used to measure upwelling in vivo fluorescence of chlorophyll a (from the uppermost $2-3 \mathrm{~m}$ of the water column) which is visible on water reflectance spectra as a Gaussian line at $685 \mathrm{~nm}$ (Gower, 1980). The flight altitude $(90 \mathrm{~m})$, aircraft forward velocity and 2 second integration time combined to give an approximate instantaneous coverage of $2 \times 100 \mathrm{~m}$ of the sea surface. Other details of the continuous measurements of the upwelling fluorescence for this $4 \mathrm{~h}$ flight are similar to those given by Borstad et al. (1980); Borstad and Brown (unpubl., 1980). The approximate conversion factor of fluorescence line height to chlorophyll a (ug $\mathrm{l}^{-1}$ ) obtained in the later reference, which may be used to evaluate actual chlorophyll values in Fig. $1 \mathrm{~B}$, is given as Fluorescence line height $\times 0.1=$ Chl a $\left(\mu \mathrm{gl}^{-1}\right)$.

Results of airborne and shipborne chlorophyll a monitoring have both been represented as a map (Fig. $1 \mathrm{~B}$ and $\mathrm{C}$ ) in order to present the data most clearly in its geographic context. The cruise tracks represent the crossing of boundary regions, the exact width of which are not known although they may sometimes be inferred from the vessel or the aircraft's passage along an adjacent body of water

Calculations for the $\log _{10}\left(h u^{-3}\right\}$ expression were based on data supplied by the Department of Fisheries and Oceans (Dr. P. B. Crean, pers. comm.). Values were estimated from a $4 \mathrm{~km}$ grid using velocities (u) generated by a large flood tide in order to show maximum differentiation in regions of turbulence and relative stability. The resulting $\log _{10}$ expression was contoured within a computer representation of the Strait of Georgia (Fig 1 A).

Zooplankton samples were collected from the same water samples used for the measurement of continuous chlorophyll fluorescence. Twenty-five samples were collected at equal distances over the entire ship's route; either 40 or $80 \mathrm{l}$ of seawater were filtered through a $175 \mu \mathrm{m}$ net and all the zooplankton in each sample were counted.

\section{RESULTS AND DISCUSSION}

\section{Areas of High Chlorophyll a}

Fig. 1 A shows the result obtained from calculating the $\left(\mathrm{hu}^{-3}\right)$ parameter. Values range from $<-2$ in the turbulent passages at both ends of the Strait to $>+2$ in the open waters at the north end of the Strait and in certain inlets and bays (e.g. Saanich Inlet). The critical frontal region of $\log _{10}\left(\mathrm{~h} \mathrm{u}^{-3}\right)$ term $\mathrm{ca}-1$ is seen to occur (heavy stripes in Fig. 1 A) at either end of the Strait as well as in passages associated with islands, particularly the Gulf Islands and in the North, across the Strait in the vicinity of Texada Island and Denman Island. Intermediate levels of stability ( 1 to 2 ) occur in open waters of the Strait. From these general observations it is apparent that variations in physical turbulence and stability suggested earlier (Parsons et al., 1980) could lead to a highly contagious distribution of chlorophyll $a$, as can now be shown in Fig. $1 \mathrm{~B}$ and $C$.

In Fig. $1 \mathrm{~B}$, the distribution of chlorophyll a fluorescence as shown by airborne measurements indicates that the 2 turbulent zones at either end of the Strait give rise to high levels of chlorophyll a during a period when much of the Strait is depleted of nutrients (Parsons et al., 1970). These areas are smeared in a direction consistent with the general circulation of the Strait. Thus, nutrient-rich water entering the Strait from the north would be generally drawn along the east of Vancouver Island giving a high standing stock of chlorophyll a as far south as Denman Island, where some island turbulence (Fig. 1 A) tends to further enhance production. From the south, nutrient-rich waters entering from Juan de Fuca and drawn under the Fraser river plume gave rise to an area of high chlorophyll a northwards along the west coast of the mainland up to Texada Island where island turbulence passages (Fig. 1 A) may again enhance primary production. This mechanism is borne out in general by the ship survey of chlorophyll a (Fig. 1 C) although some details differ in respect to the location of actual boundaries. This may be attributable to the different depth of water sampled by the vessel compared with the aircraft survey, or differences in the timing of the two surveys. The aircraft survey took place August 2 while the ship covered the period July 28 to August 2.

Neither the aircraft survey nor the ship survey showed high concentrations of chlorophyll a in the Gulf Islands during the period July 28 to August 2, although 2 small increases in the concentrations of chlorophyll a were encountered by the aerial survey on the approaches to Saanich Inlet. However, on July 23 during a precruise survey in connection with this study, a large phytoplankton bloom (chl. a $12 \mathrm{mg} \mathrm{m}^{-3}$ ) was observed to occur in the inter-island passages. In addition, Takahashi et al. (1977) have studied the occurrence of summer phytoplankton blooms entering Saanich Inlet and their results show them to be transitory, increasing to chlorophyli levels of $>5 \mathrm{mg} \mathrm{m}^{-3}$ at 1 or 2 week intervals and decreasing to chlorophyll levels of $<1 \mathrm{mg} \mathrm{m}^{-3}$ during intervening periods. Thus, while the major productive zones in the Strait appear to be well established for the 2 ends of the Strait, the inter-island turbulence/stability relationships are going to be more difficult to diagnose. However, in 

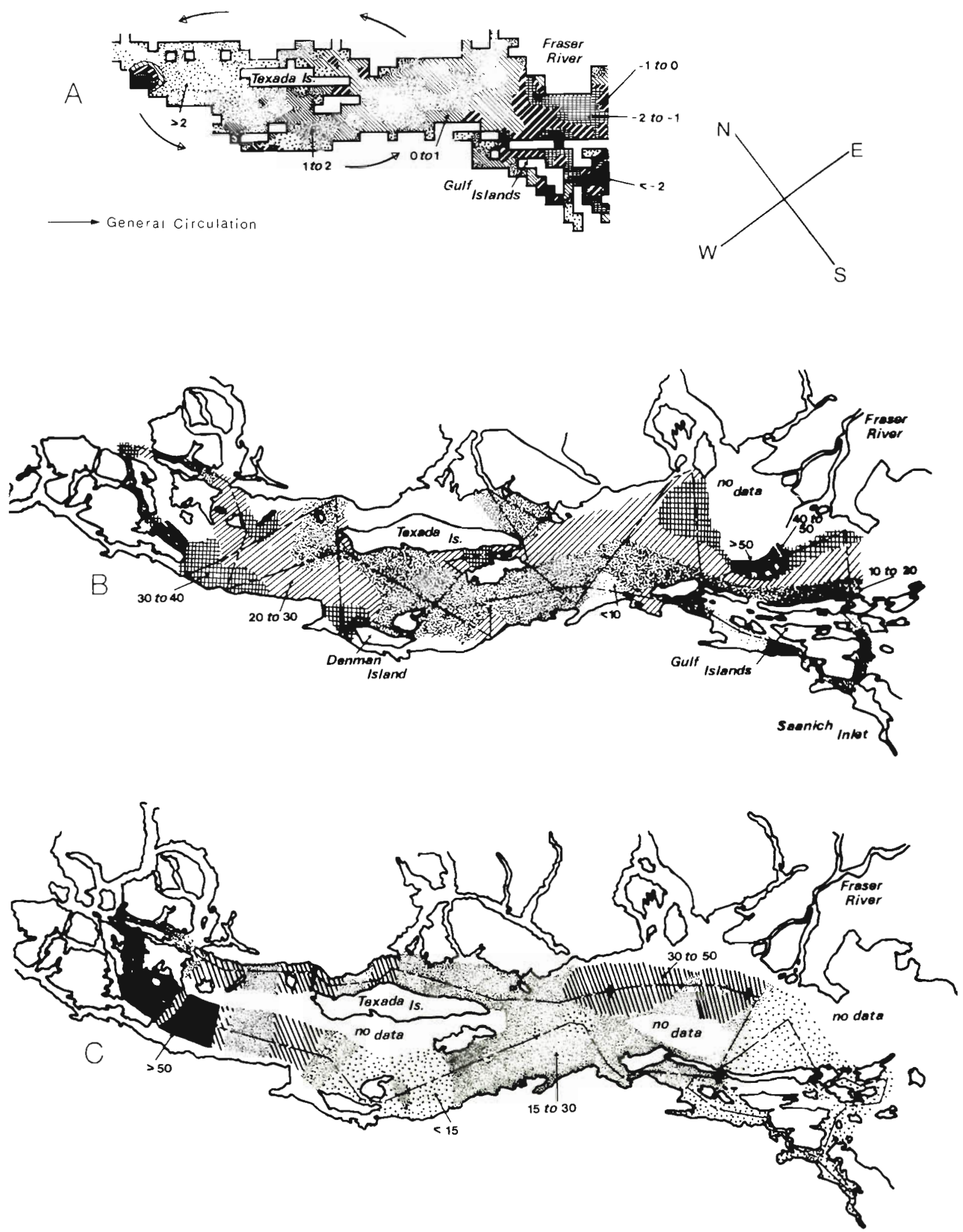

Fig. 1. (A): $\log _{10}\left(\mathrm{~h} \mathrm{u}^{-3}\right.$ ) calculated over a $4-\mathrm{km}$ grid for the Strait of Georgia during a flood tide. (B): Chlorophyll fluorescence as seen by an aerial survey, Aug. 2, 1980. (C): Chlorophyll fluorescence as seen by a ship survey, July 28-Aug. 2, 1980 (Chlorophyll $a$ in $\mu \mathrm{g} \mathrm{l}^{-1}$ can be approximated from the measured chlorophyll fluorescence by dividing the fluorescence value by a factor of 10 ) 
both this paper and Takahashi et al. (1977) there is a similarity with respect to the type of primary producers in that the high chlorophyll a values were generally associated with diatom production.

Pingree (1978) described the critical number at which chlorophyll a maximized as $\log _{10}\left(\mathrm{~h} \mathrm{u}^{-3}\right)=-1.0$ (that is, excluding the $\mathrm{C}_{d}$ term as being essentially similar for both areas). In order to evaluate this conclusion for the Strait of Georgia, chlorophyll a fluorescence at each station was averaged for stations falling in the $\left(\mathrm{hu}^{-3}\right)$ water masses, $<-2,-2$ to -1 , etc. The result shown in Fig. 2 A indicates a general increase in the average chlorophyll fluorescence $<-2$ to $>2$. Using a t-test of means, there was a highly significant difference between the mean chlorophyll fluorescence between stations $<-1$ to 0 and those having $\left(\mathrm{hu}^{-3}\right)$ values $>0$ to 1 . Above an $\left(\mathrm{h} \mathrm{u}^{-3}\right)$ term of 0 , there appear to be, in fact, two chlorophyll maxima, the one associated with areas immediately adjacent to the boundary
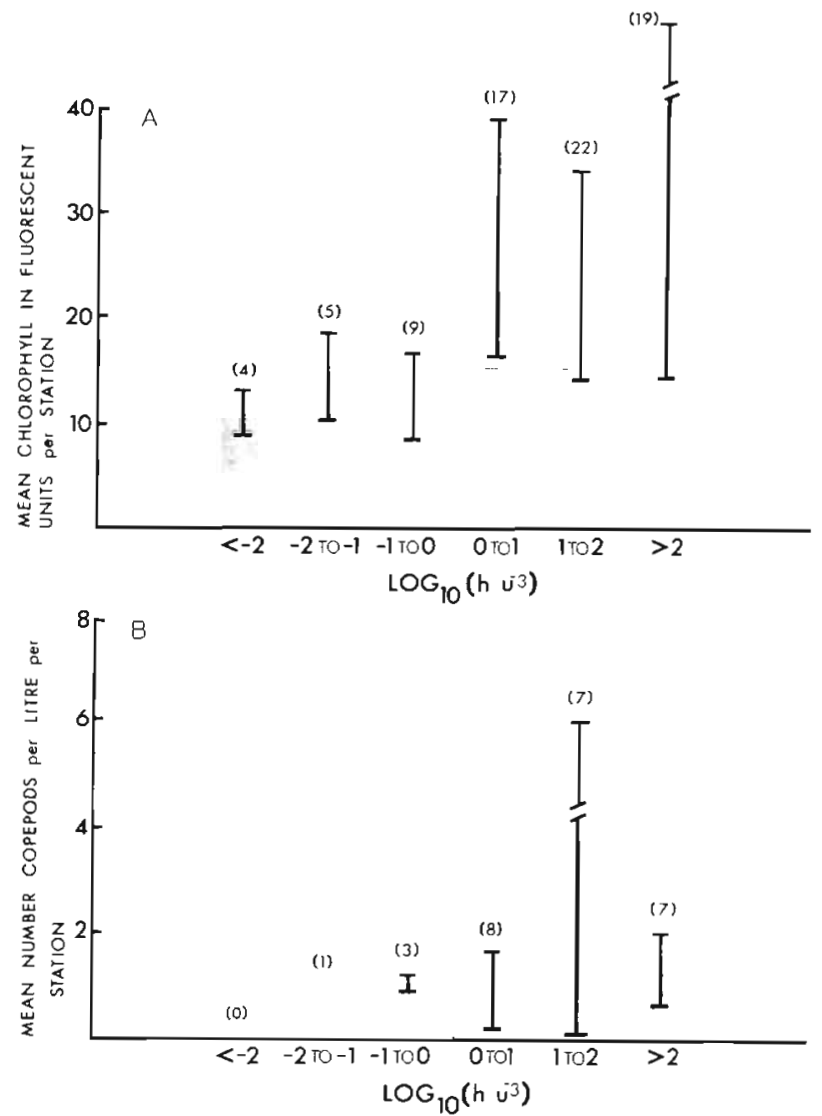

Fig. 2 (A): Mean chlorophyll fluorescence per station from 76 stations taken equidistant along the ship's cruise track (Fig. $1 \mathrm{C})$ and related to the regions of relative stability shown in Fig. 1 A. (B): Mean number of copepods $1^{-1}$ in surface samples taken from 24 stations equidistant along the cruise track (Fig. $1 \mathrm{C})$ and related to regions of relative stability shown in Fig. 1 A. Standard deviation of each mean is shown as bar; number of samples contributing to the mean shown in brackets region of $>-1$ and the other in more stable water where the $\left(\mathrm{h} \mathrm{u}^{-3}\right)$ term is $>2$. As a further complication in this pattern it appears from Fig. $2 \mathrm{~B}$ that the maximum numbers of copepods occur at an intermediate position between the 2 maxima, i.e. in a stability region characterized by the $\left(\mathrm{h} \mathrm{u}^{-3}\right)$ term of 1 to 2 .

The most logical explanation for these observations appears to be as follows:

(1) The critical boundary region suggested by Pingree (1978) of -1 appears to be generally applicable to the Strait of Georgia although some chlorophyll can be found in turbulent waters having $\left(\mathrm{h} \mathrm{u}^{-3}\right)$ values of $<-1$. This fact, together with the 2 maximizations of chlorophyll $a$ at values at 0 to 1 and $>2$ appears to be related to two additional factors; one is the absolute water depth over which the boundary region of $\left(\mathrm{h} \mathrm{u}^{-3}\right)$ $=-1$ occurs, the other is the role of freshwater in stabilizing the water mass; a factor not considered in Pingree's original paper where a uniform heat flux, $Q$. was considered the only source of stabilization.

Pingree et al. (1978) discuss the first of these factors, i.e. the effect of total depth on the relationship between $\left(\mathrm{h} \mathrm{u}^{-3}\right)$ and chlorophyll. These authors show that over deep water (ca. $100 \mathrm{~m}$ ) chlorophyll a maximum is reached at some distance from the critical $\left(\mathrm{h} \mathrm{u}^{-3}\right)$ value of -1 . In fact in their example of a deep water front in the region of Orkney-Shetland Isles (their Fig. 5) the chlorophyll a maximum occurs in water which has $\log _{10}\left(\mathrm{~h} \mathrm{u}^{-3}\right)$ values of -0.5 to 0 , that is on the more stratified side of the front. In shallow water, however, the authors show that for Flamborough Head (their Fig. 4) the chlorophyll a maximum tends to occur in water less stable than indicated by the -1 value, i.e. in the region -1.5 .

In the Strait of Georgia the 2 main mixing zones at the northern and southern end of the Strait (Fig. 1 A) are over water $>100 \mathrm{~m}$ depth, and it is therefore logical to find the chlorophyll a maximum occurring at higher stability values than indicated by the critical - 1 value, which is consistent with Fig. 2 A. However, the actual position of the chlorophyll maximum relative to the stability term really depends on the extinction coefficient of the water and the presence of other stabilizing influences, such as the flow of fresh water from the Fraser River which is discussed below. On the other hand, the transient chlorophyll a maxima which are observed in the region of the Gulf Islands as discussed above, may occur where the water depth is considerably $<100 \mathrm{~m}$ and consequently some chlorophyll is observed to be present in Fig. $1 \mathrm{~B}$ at stability values well below -1 .

(2) The problem of explaining why there are apparently 2 maxima in the chlorophyll/stability diagram (Fig. 2 A) can now be further examined in terms of the influence of the Fraser River including both its con- 
tribution of freshwater to stability, and the effect on the extinction coefficient which is governed in part by the silt load.

Mackas et al. (1980) pointed out that for the Strait of Georgia, uniform heating (Q) may be less important than freshwater stratification, at least in the southern part of the Strait where the Fraser River plume extends over a wide area. Most of the stations having a chlorophyll fluorescence maximum in the $\left(\mathrm{h} \mathrm{u}^{-3}\right)$ region, 0 to 1 (Fig. 2 A) lay in the area south of Texada Island while those having a high chlorophyll fluorescence in $\left(\mathrm{h} \mathrm{u}^{-3}\right)=>2$ region lay north of Texada Island. Thus on the basis of stability alone it appears that the influence of freshwater in the southern part of the Strait causes a chlorophyll maximum to occur in more recently upwelled water $\left(\log _{10}\left[\mathrm{~h} \mathrm{u}^{-3}\right]=0\right.$ to 1$)$ than in the northern part of the Strait where heating is largely responsible for stabilization. As a verification of this hypothesis, chlorophyll fluorescence can be shown to be correlated with surface temperature $(\mathrm{r}=$ 0.75) for 21 stations north of Texada Island but only poorly with surface temperature ( $\mathrm{r}=0.21$ ) for 21 stations south of Texada Island.

To further account for general displacement of high chlorophyll values into more stable water bodies than indicated by the $\log _{10}\left(\mathrm{~h} \mathrm{u}^{-3}\right)$ term of -1.0 , it is necessary to compare the extinction coefficients for the area in which Pingree (1978) developed his critical parameter, i.e. the Celtic Sea as compared with the Strait of Georgia. Pingree et al. (1976) give extinction coefficient values of 0.11 to 0.23 ; comparing the same time period for the Strait of Georgia, Parsons (MS 1965) gives a range of values from 0.14 to 0.85 . Since the penetration of light into the water column is as much a necessary factor in producing chlorophyll as is the stabilization of previously mixed water masses, it can be argued that the higher extinction coefficients found in the Strait of Georgia will generally result in a slower growth of phytoplankton following a mixing process and consequently the maximum in the chlorophyll values in Fig. $2 \mathrm{~A}$ will tend to be shifted to values above the critical value of -1.0 used by Pingree (1978).

(3) Finally, the effect of zooplankton grazing on the distribution of chlorophyll a has to be considered in relation to Fig. 2. Pingree et al. (1974) found that the distribution of herbivorous copepods was directly associated with maxima in chlorophyll a. On the other hand, Mackas et al. (1980) established an inverse relationship between zooplankton and chlorophyll fluorescence. The difference between these 2 results is probably largely accounted for by the temporal/spatial scales of sampling and both relationships can be considered correct (c.f. Parsons et al. 1977, p. 160). In the studies reported here, the maximum numbers of copepods (Fig. 2 A) appear to lie between the 2 chlorophyll maxima in Fig. $1 \mathrm{~B}$. This could be interpreted as indicating an association of the maxima in chlorophyll a with some spatial distribution of herbivorous copepods similar to that found during the spring off the Fraser River plume (Parsons et al., 1969). At that time of year the zooplankton are found in maximum numbers on the outer edge of the chlorophyll maximum produced by the spring bloom and their presence can generally be regarded as causing a depression in the standing stock of chlorophyll.

\section{Relationship Between Chlorophyll a Distribution and Primary Productivity}

In the discussion above it has been shown that frontal mixing processes occur in the Strait of Georgia and that these result in areas of high chlorophyll a. Following the explanation given by Pingree (1978), these frontal mixing processes cause nutrients to be brought to the surface which in turn result in high primary productivity, particularly during the summer months, and finally in an increased standing stock of chlorophyll a as shown in Fig. $1 \mathrm{~B}$ and C. In a recent publication Stockner et al. (1979) showed an apparent $300 \%$ increase in the average primary productivity for the Strait of Georgia compared with results reported by Parsons et al. (1970). Stockner et al. (1979) suggested 'that nutrients necessary to support the magnitude of phytoplankton now (Stockners's italics) seen in back eddies and plume boundaries may largely be derived from nitrate and ammonia from the Fraser River and adjoining tidal lands, and secondarily from seawater by physical processes'. From our calculations (Parsons et al., 1980) the actual contribution of Fraser River nutrients to the Strait of Georgia, even under the most favourable allowances of a geographically restricted effect, could not amount to more than a $30 \%$ increase in primary productivity - a point which Stockner et al. (1980) appear to have subsequently accepted. In fact the occurrence of high chlorophyll fluorescence in the northern part of the Strait of Georgia (an area not studied in Stockner et al.'s, 1979 survey) indicates that such areas of high phytoplankton are not a result of eutrophication (since there is no source of nutrients in the northern part of the Strait as there is from the metropolitan area of Vancouver in the south). Rather, it appears that in the northern part of the Strait the basic control of primary productivity is through the natural mechanism of frontal boundary conditions. In the southern part, frontal boundary conditions, nutrient entrainment by the Fraser River (Parsons et al., 1969) and a nutrient input from the river itself (Stockner et al., 1979) all contribute to the primary productivity. These effects are most apparent during the summer months. 
The lesson to be learned from these studies is that standard reference stations are probably not the best way to represent the primary and secondary productivity of the Strait of Georgia. This is because there are many frontal boundaries of high production in the Strait which move with each tidal cycle as well as with the general circulation. Routine sampling stations which are placed close to these boundaries, as suggested by Parsons et al. (1980) in the work of Stockner et al. (1979), will tend to give high values for primary productivities. Conversely, stations located well inside inlets (e.g. Saanich Inlet and Pendrell Sound, as well as in some open waters of the Strait, Parsons et al., 1970) may tend to give low primary productivities.

Acknowledgements. The authors would like to acknowledge financial assistance from the NSERC, Ships of Opportunity Strategic grant and for technical assistance from Ms. E. Nutbrown. Zooplankton samples were counted and identified by Dr. C. M. Lalli. We are grateful to Dr. J. Gower for the loan of the colour spectrometer and to Dr. P. B. Crean for making physical data available to us.

\section{LITERATURE CITED}

Borstad, G. A., Brown, R. M. (MS 1980). Airborne remote sensing of sea surface chlorophyll and temperature along the B. C. Outer Coast. Unpubl. report by Seakem Oceanography to Dept. Fish. Oceans

Borstad, G. A., Brown, R. M., Gower, J. F. R. (1980). Airborne remote sensing of sea surface chlorophyll and temperature along the outer British Columbia coast. Sixth Canadian Symposium on Remote Sensing, Halifax, N. S. May 21-23, 1980

Gower, J F. R. (1980). Observations of in situ fluorescence of chlorophyll a in Saanich Inlet. Boundary Layer Meteorology 18: 235-245

Mackas, D. L., Louttit, G. C., Austin, M. J. (1980). Spatial distribution of zooplankton and phytoplankton in British Columbian Coastal Waters. Can. J Fish. Aquat. Sci. 37 : 1476-1487

Parsons, T R. (MS 1965). A general description of some factors governing primary productivity in the Strait of
Georgia, Hecate Strait and Queen Charlotte Sound, and the N. E. Pacific Ocean. MS Rept. Ser. No. 193. Fish. Res. Bd Can.

Parsons, T R., Stephens, K., LeBrasseur, R. J. (1969). Production studies in the Strait of Georgia. I. Primary production under the Fraser River plume. February to May, 1967. J. exp. mar. Biol. Ecol. 3: 27-38

Parsons, T. R., LeBrasseur, R. J., Barraclough, W. E. (1970). Levels of production in the pelagic environment of the Strait of Georgia: A review. J. Fish. Res. Bd Can. 27: $1251-1264$

Parsons, T R., Takahashi, M., Hargrave, B. (1977). Biological oceanographic processes, 2nd ed., Pergamon Press, New York

Parsons, T R., Albright, L. J., Parslow, J. (1980). Is the Strait of Georgia becoming more eutrophic? Can. J. Fish. Aquat. Sci. 37: 1043-1047

Pingree, R. D., Forster, G. R., Morrison, G. K. (1974). Turbulent convergent tidal fronts. J. mar. biol. Ass. U.K. 54: 469-479

Pingree, R. D., Holligan, P. M., Mardell, G. T., Head, R. N (1976). The influence of physical stability on spring, summer and autumn phytoplankton blooms in the Celtic Sea. J. mar. biol. Ass. U.K. 56: 845-873

Pingree, R. D., Holligan, P. M., Mardell, G. T. (1978). The effect of vertical stability on phytoplankton distributions in the summer on the Northwest European Shelf. Deep Sea Res. 25: 1011-1028

Pingree, R. D. (1978). Mixing and stabilization of phytoplankton distributions on the Northwest European continental shelf. In: Steele, J. H. (ed.) Spatial pattern in plankton communities. Plenum Press, New York, pp. 181-220

Stockner, J. G., Shortreed, J. S., MacIsaac, E. A. (1980). The benevolent Strait: Reply. Can. J. Fish. Aquat. Sci. 37: $1048-1055$

Stockner, J. G., Cliff, D. D., Shortreed, J. S. (1979). Phytoplankton ecology of the Strait of Georgia, British Columbia. J. Fish. Res. Bd Can. 36: 657-666

Strickland, J. D. H., Parsons, T. R. (1972). A practical handbook of seawater analysis. Bull. Fish. Res. Bd Can. 167 : $1-310$

Takahashi, M., Seibert, D. L., Thomas, W. H. (1977). Occasional blooms of phytoplankton during summer in Saanich Inlet, B. C., Canada. Deep Sea Res. 24: 775-780

Walker, G. A. H., Buchholz, V L., Camp, D., Isherwood, B., Glaspey, J., Coutts, R., Condal, A., Gower, J. F. R. (1974). A compact multichannel spectrometer for field use. Rev. Sci. Instrum. 45: 1349-1352 